\title{
AGRAVOS RESPIRATÓRIOS E O CLIMA EM UBERLÂNDIA/MG NO ANO DE 2015
}

\author{
Lara Lane de Oliveira ${ }^{(a)}$, Adria Rodrigues Fontes ${ }^{(b)}$, Rafael de Ávila Rodrigues ${ }^{\text {(c) }}$ \\ (a) Programa de Pós Graduação/ Universidade Federal de Goiás - Regional Catalão, Mestranda do \\ Programa de Pós-Graduação em Geografia. llaneo.p@gmail.com \\ (b) Programa de Pós Graduação/ Universidade Federal de Goiás - Regional Catalão, Mestranda do \\ Programa de Pós Graduação em Geografia. adria1969@gmail.com \\ (c) Programa de Pós Graduação/ Universidade Federal de Goiás - Regional Catalão, Professor Doutor do \\ Programa de Pós Graduação em Geografia, rafael.avila.roodrigues@gmail,com
}

\section{Eixo: Climatologia em Diferentes Níveis Escalares: Mudanças e Variabilidade}

\begin{abstract}
Resumo
Este artigo visa analisar a possível relação entre os agravos respiratórios em menores de cinco anos e o clima no município de Uberlândia/MG. Considerando variáveis como temperatura e umidade do ar sua influência nas condições ambientais no meio urbano e na incidência dos casos de bronquite e asma. Para isto, foram coletas junto a Secretária de Saúde do município através da Vigilância Ambiental os casos registrados de agravos respiratórios em menores de cinco anos no ano de 2015- e posteriormente os dados coletados no departamento de climatologia da Universidade de Uberlândia foram tratados e organizados e analisados.
\end{abstract}

Palavra chave: Doenças respiratórias, clima, Uberlândia- MG

\section{Introdução}

Com o processo de urbanização e industrialização mudou a paisagem natural causando impacto no ambiente. A atividade industrial e o crescimento demográfico acelerado contribuem para um serie de problemas ambientais, e de saúde nas populações das cidades. Essas populações sofrem com maior intensidade os fenômenos da natureza, muitas vezes potencializado pelas alterações antropológicas no ambiente das cidades.

Toda essa ordem e transformações produzidas na paisagem local reflete diretamente no equilíbrio entre a superfície terrestre e a atmosfera a ela adjacente. Modificando as condições climáticas nas mais diversas escalas. Fenômenos ligados aos eventos climáticos extremos, como enchentes e deslizamentos de encostas, poluição atmosférica e à configuração das chamadas ilhas de calor urbanas são alguns dos resultados das novas condições ambientais vivenciadas na modernidade, principalmente nas cidades tornando sua população cada vez mais vulnerável. (CAJAZEIRA, 2012)

Segundo a organização Pan- Americana da Saúde em 2009 os problemas de saúde humana associados à mudança climáticas podem não ter sua origem necessariamente nas alterações climáticas, mas sim, nas alterações que a terra pode sofrer a partir dela, além dos eventos extremos as mudanças no 
ambiente como a alteração de ecossistemas e de ciclos biológicos, geográficos, e químicos, podem aumentar a incidência de doenças infecciosas e também doenças não transmissíveis.

Para Confalonieri (2003), o clima pode atua sobre a saúde das pessoas de duas formas básicas, relativa á sucessão regular do clima com influência sobre o comportamento biológico que poderia culminar, por exemplo, em casos de doenças respiratórias ou facilitar a recuperação das mesmas.

Os elementos do clima que afetam mais diretamente as funções fisiológicas do homem incluem a radiação solar, temperatura, umidade do ar, além do vento e da pressão atmosférica. A temperatura elevada e alta umidade ou a temperatura baixa e umidade baixa tende a diminuir a energia física e mental do homem.(AYOADE, 2010).

Dentre as ações ligadas ao clima, que pode influenciam o meio ambiente e pode prejudicar a saúde humana estão a pratica das queimadas urbanas que ocorrem no período onde as precipitações são escassas.Arbex et al (2004) discutem que a queima de biomassa e os problemas que a mesma traz a saúde humana, de forma especial as doença respiratórias. Por vezes é praticado para suprir a demanda das administrações que não conseguem abranger todo o município com a coleta de resíduos sólidos e a limpeza de terrenos, então a população se encarrega da "limpeza" ateando fogo nos terrenos. Pratica que tem um preço alto para a saúde dos munícipes.Segundo o professor DrEdsomDelatre (2004), do Instituto de Biologia da Universidade Estadual de Campinas (Unicamp) em uma entrevista a Revista Eletrônica Boavontade.com , afirma que:

“infelizmente, as queimadas urbanas são frequentíssimas devido a uma cultura que muitos têm: descartar diversos tipos de dejetos em terrenos baldios e queimá-los. Dessa forma, o fogo se espalha causando incêndios, além da fumaça que contém diversas substâncias tóxicas - até mesmo cancerígenas - ao sistema respiratório". (DELARTRE,2004)

Ainda segundo Arbex et al (2004) indivíduos portadores de patologias respiratórias crônicas mostramse mais susceptíveis aos efeitos da poluição gerada pela queima de vegetação, fato de que muitos pacientes com doenças crônicas do aparelho respiratório, principalmente bronquite crônica, enfisema, e asma, referem agravamento dos seus sintomas no período do ano que coincide com a queimada da cana. Mas não é só. Indivíduos hígidos, na mesma época do ano, referem, com frequência, irritação em vias aéreas superiores com ardor no nariz e na garganta. A presença na atmosfera de resíduos grosseiros resultantes da combustão da cana-de-açúcar aparece, para a população em geral, como a evidência de que os sintomas respiratórios dependem ou são agravados pela poluição ambiental gerada pelas queimadas. 


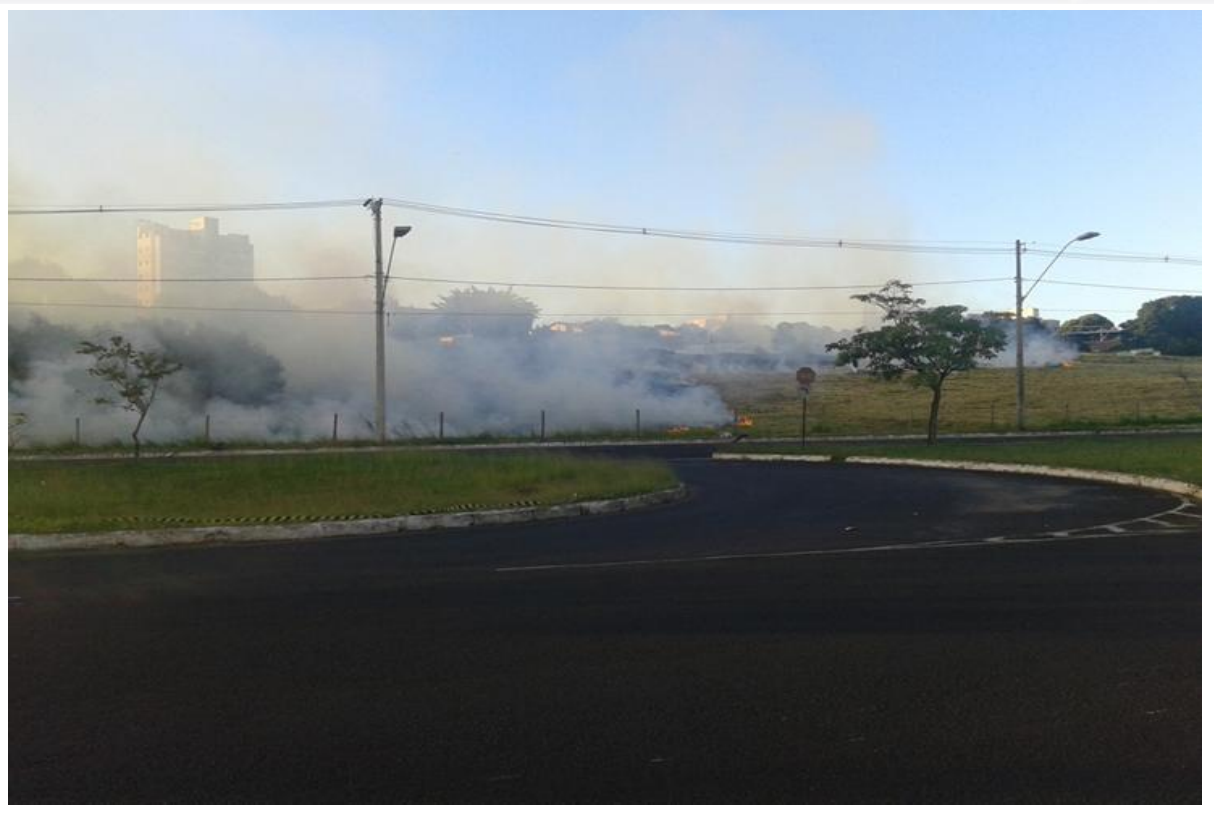

Figura 1: Mostra Queimada Urbana em Uberlândia - MG

Fonte: Oliveira, L.L. 2016

O grande número de terrenos baldios no município, favorece as queimadas urbanas que se tornou uma pratica cultural, colocar fogo em resíduos de capina, poda de árvores e em lixo seco nos quintais. Por vezes é praticada para suprir a demanda das administrações que não conseguem abranger todo o município com a coleta de resíduos sólidos e a limpeza de terrenos, então a população se encarrega da "limpeza" ateando fogo nos terrenos. Pratica que tem um preço alto para a saúde dos munícipes.

Essas variáveis climáticas podem, igualmente, aumentar a duração da exposição aos poluentes e impedir sua dissipação, atribuindo-se a elas um efeito adicional sobre a mortalidade em pacientes asmáticos. Um exemplo é a forte correlação entre concentração de ozônio e temperatura elevada, pois em dias ensolarados e em locais poluídos há aumento da concentração desse gás na atmosfera. (SALDANHA E BOTELHO, 2008).

Mendonça, (2000) ressalta que o clima é um importante componente da natureza responsável pela dinâmica do ambiente e que a relação do individuo com o clima, acontece especialmente pelo aparelho respiratório, que é o aparelho do corpo humano que tem maior relação com o meio ambiente.

$\mathrm{Na}$ área urbana variação climática potencializam os poluente atmosféricos, principalmente quando ocorrem a inversões térmicas, onde os poluentes não se dissipam e permanecem junto a superfície, prejudicando os grupos de pessoas mais susceptíveis que são as crianças abaixo de cinco anos e os idosos acima de 65 anos de idade. 


\section{Materiais e Métodos}

O clima de Uberlândia (MG) que está inserida na região do Triangulo Mineiro, segundo a classificação de Köppen, é do tipo AW o que significa que possui um inverno seco e um verão chuvoso. Na estação de seca que se estende de maio a setembro é a que se faz sentir como o período de maior sensação de desconforto para a população devido a baixa umidade relativa do ar ao aumento de poeira em suspensão.

O clima que caracteriza a região do Triângulo Mineiro, na qual Uberlândia está inserida, possui um inverno seco e um verão chuvoso (Mendes, 2001).

Segundo Silva (2013), em seu trabalho "A cidade e o Clima: impacto das precipitações concentradas e tendências climáticas da cidade de Uberlândia", cita que a média no Município durante o período de (1981 a 2011) foi em média de $22,5{ }^{\circ} \mathrm{C}$ e a umidade mantendo a média em $69 \%$.

Ribeiro (2000) comenta que o município sofre com os problemas relacionados com as baixas taxas de umidade relativas do ar presente nas tarde dos dias da estação seca quando não são raros os valores inferior a $20 \%$.

É nesse período que acontece com maior frequência ás queimadas urbanas que causam impacto na qualidade de vida dos munícipes.A cidade de Uberlândia passou por um intenso crescimento populacional apartir da década de 1970, devido ao incentivo econômico para a modernização e expansão da agropecuária, que operou transformações na área do cerrado(GUIMARÃES,1990).

Influenciando assim o crescimento da economia municipal com geração de centros atacadistas em seu entorno e aumento da malha rodoviária para escoar a produção.

No espaço urbano, como aconteceu nos grandes centros, se estruturou de forma a aglomerar as atividades econômicas e segregar as classes sociais. Bairros sofisticados, condomínios com toda infraestrutura para abrigar a população de media e alta renda e por outro lado produziu bairros extremamente carente de serviços básicos e um intenso crescimento dos loteamentos periféricos, com inúmeros terrenos vagos devida a politica de especulação imobiliária, (MOTA,2011).

A cidade de Uberlândia está localizada na porção sudoeste do Estado de Minas Gerais, na região do Triângulo Mineiro (Mapa 1) na intersecção das coordenadas geográficas 1855'23'” de latitude Sul e 4817'19" de longitude Oeste de Greenwich, no domínio dos Planaltos e Chapadas da Bacia Sedimentar do Paraná, na porção Sudoeste do Cerrado brasileiro, a uma altitude média de $865 \mathrm{~m}$, ocupando uma área de 2019 Km2 dentro do Município de 4.115 Km2 (SILVA,2004). 

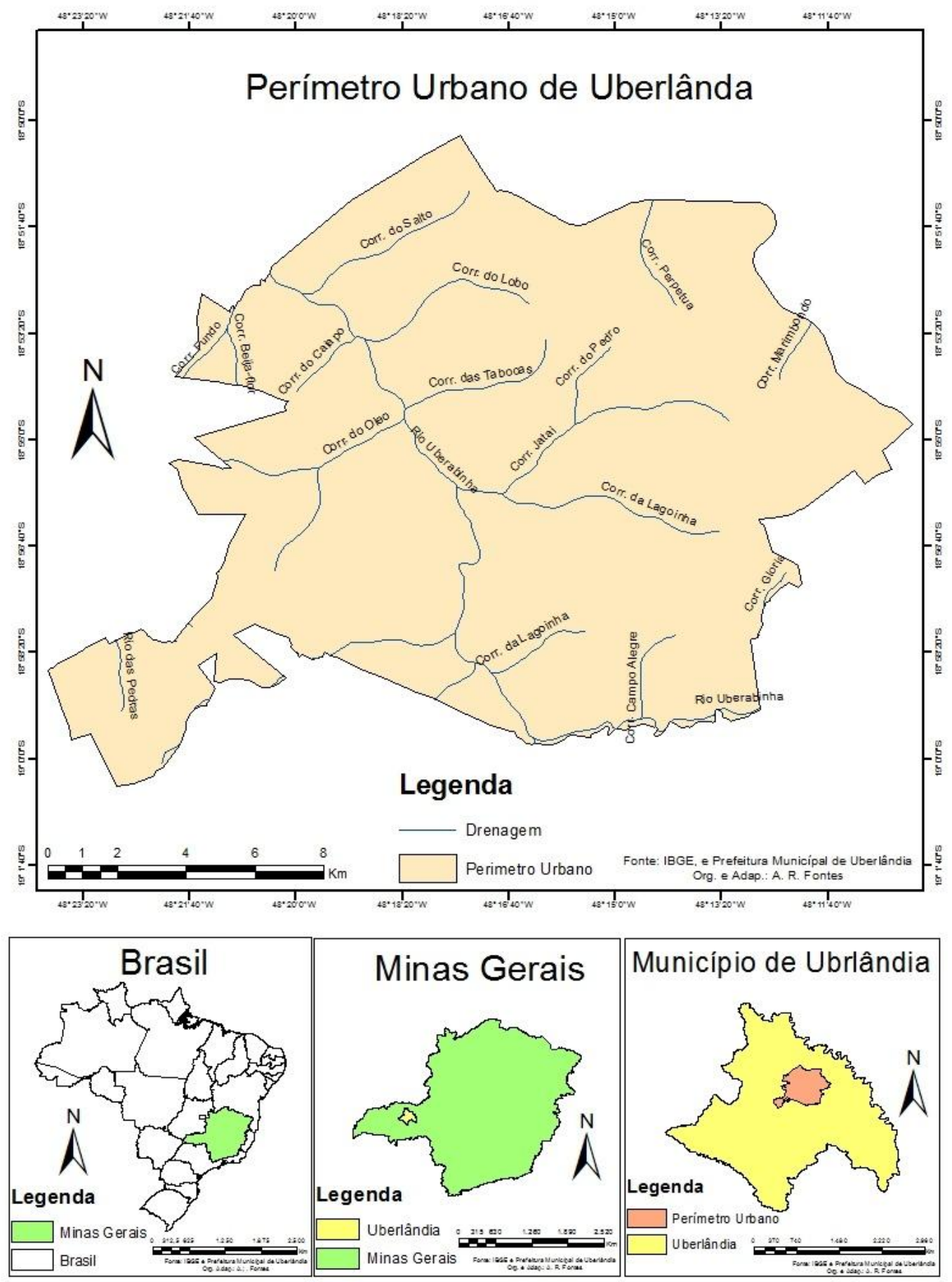

Figura 2 - Mapa da área do Perímetro Urbano de Uberlândia Fonte IBGE Org: F,.A.R

\section{Resultado e discussões}


Os dadossobre agravos respiratórios foram obtidos na Secretaria de Saúde Municipal pelos boletins epidemiológicos da Vigilância Ambiental que tem como fonte a unidade de saúde UAI ROOSEVELT (Dr Josias de Freitas) que é a unidade de saúde foi escolhida pelo município para ser referência em notificação de agravos respiratórios no município, chamada de unidade de sentinela para a vigilância da qualidade do ar através de notificações dos agravos. Esta unidade de saúde recebe crianças de todas as regiões da do município e zona rural e distritos.

Foram escolhidos o foram retirados do boletim epidemiológico que e feito por quadrimestre, sendo o $1^{\circ}$ quadrimestre abrangendo os meses de janeiro à abril, o $2^{\circ}$ quadrimestre de maio à agosto e o $3^{\circ}$ de setembro à dezembro.

A escolha das doenças, asma e bronquite se deu por se apresentarem no boletim epidemiológico com maior frequência em todos os meses.

Asma segundo o Caderno de Atenção Básica - 2010 cita que é uma doença inflamatória crônica, caracterizada por hiper-responsividade das vias aéreas inferiores e por limitação variável ao fluxo aéreo, reversível espontaneamente ou com tratamento. É uma condição multifatorial determinada pela interação de fatores genéticos e ambientais.

Bronquite segundo Varella (2013) bronquite consiste na inflamação das principais passagens de ar para os pulmões. A bronquite pode ser aguda (curta duração) ou ser crônica dura por muito tempo e tem alta recorrência. A aguda costuma acompanhar uma infecção viral respiratória. No início, ela afeta o nariz, os seios da face e a garganta, depois, se espalha para os pulmões.As crises também podem ser desencadeadas pelo contato com poluentes ambientais e químicos (poeira, inseticidas, tintas, ácaros, etc.).

Em Uberlândia na unidade referência para as notificações foram registrados no ano de 2015 1469 casos de asma e bronquite como mostra a tabela 1 a seguir:

Tabela 1: Casos de agravos respiratórios no ano de 2015 por quadrimestre.

\begin{tabular}{|l|l|l|l|l}
\hline Agravos & $\begin{array}{l}\mathbf{1}^{\mathbf{0}} \\
\text { Quadri }\end{array}$ & $\mathbf{2}^{\mathbf{0}}$ Quadri & $\mathbf{3}^{\mathbf{0}}$ Quadri & Total \\
\hline Asma & 177 & 298 & 53 & 528 \\
\hline Bronquite & 150 & 614 & 177 & 941 \\
\hline Total & 327 & 912 & 230 & 1469
\end{tabular}

Fonte: Boletim Epidemiológico Secretária Municipal de Saúde - 201 
Na tabela 1 pode se observar que no $2^{\circ}$ quadrimestre que abrange os meses de maio a agosto houve um aumento na procura ao atendimento em saúde ligada aos problemas respiratórios, esses meses compreende o período de seca em que as queimadas urbanas são mais constantes.

Figura 3: Casos de Asma por quadrimestre no ano de 2015

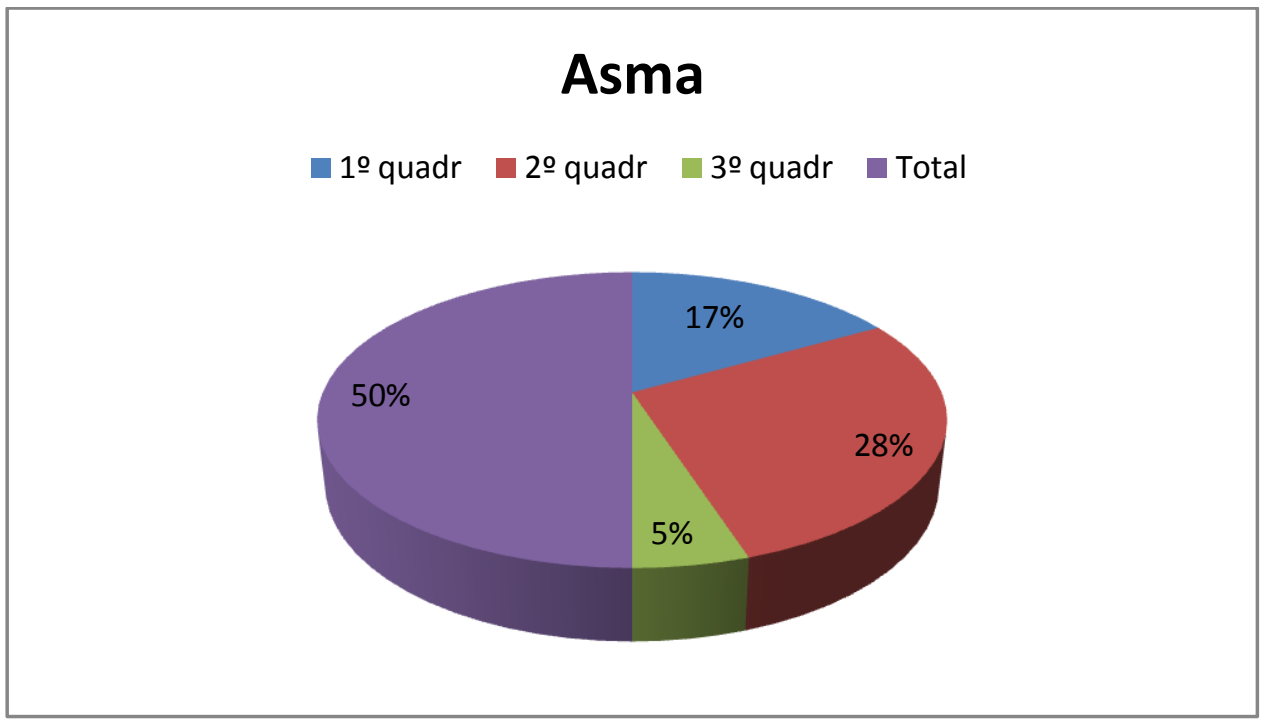

Fonte: Boletim Epidemiológico Secretária Municipal de Saúde - 2015

Figura4: Casos de Bronquite por quadrimestre no ano de 2015

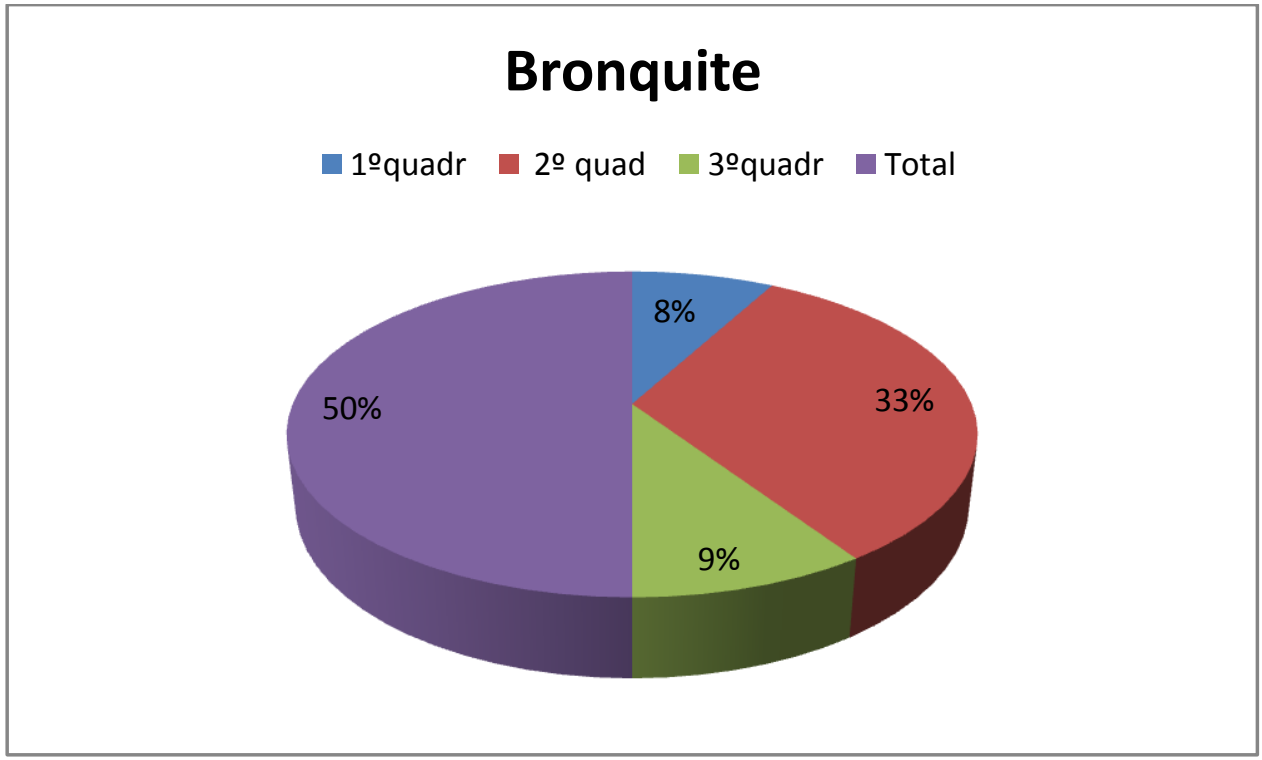

Fonte: Boletim Epidemiológico Secretária Municipal de Saúde - 2015 


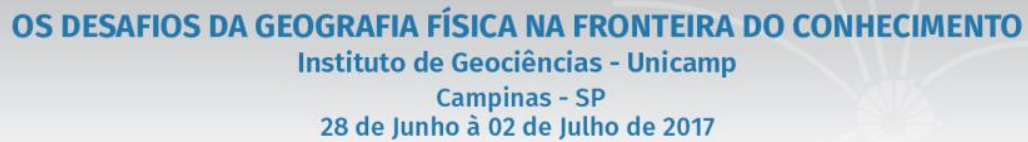

A temperatura do ar é um dos efeitos mais importantes da radiação terrestre. Esta é definida como a quantidade de calor sensível presente no ar atmosférico através do aquecimento da superfície (AYOADE, 2010).

A temperatura media na cidade de Uberlândia - Minas Gerais no período analisado é de $22,3^{\circ} \mathrm{C}$, tendo media mínima registra da em junho de $20,8^{\circ} \mathrm{C}$ e a media máxima em outubro de $27,7^{\circ} \mathrm{C}$ conforme dados da Estação automática da Universidade de Uberlândia. O gráfico da figura 5 mostra a temperatura media por quadrimestre.

Figura5: Media de Temperatura por quadrimestre no ano de 2015

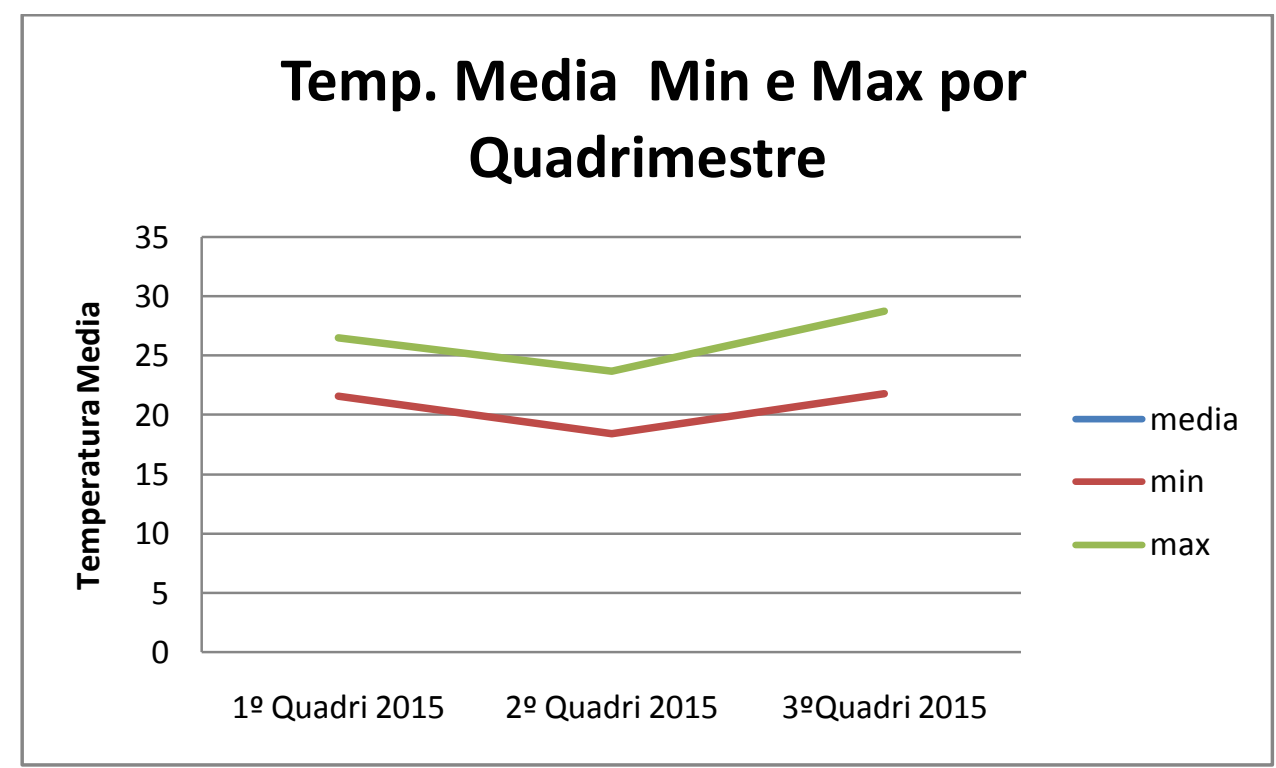

Fonte: Universidade Federal de Uberlândia- Departamento de Climatologia Org: Oliveira,L.L

Umidade relativa é de maneira geral, a medida do ar mais popularmente divulgada e utilizada nos setores que necessitam dessa informação. Os instrumentos utilizados são os termômetros de mercúrio, de bulbo seco e de bulbo úmido. O resultado desta variável descreve o grau de saturação do ar, sendo fortemente influenciada pela temperatura do ar. (Ayoade, 2010).

A media da umidade relativa do ar no ano de 2015 no município de Uberlândia foi de 50\%, sendo a menor media registrada em agosto com 40,6\% e a maior em março de 79,6\%. Segundo Silva(2004), índices acima de $90 \%$ dificultam a transpiração humana, bem como índices abaixo de $40 \%$ são agressivos a saúde humana. Durante o mês de julho a umidade mínima registrada foi de 20,2\% a menor do ano segundo dados da estação automática da Universidade Federal de Uberlândia.

Figura 6: Variação Entre a Umidade Máxima e Mínima por quadrimestre no ano de 2015 


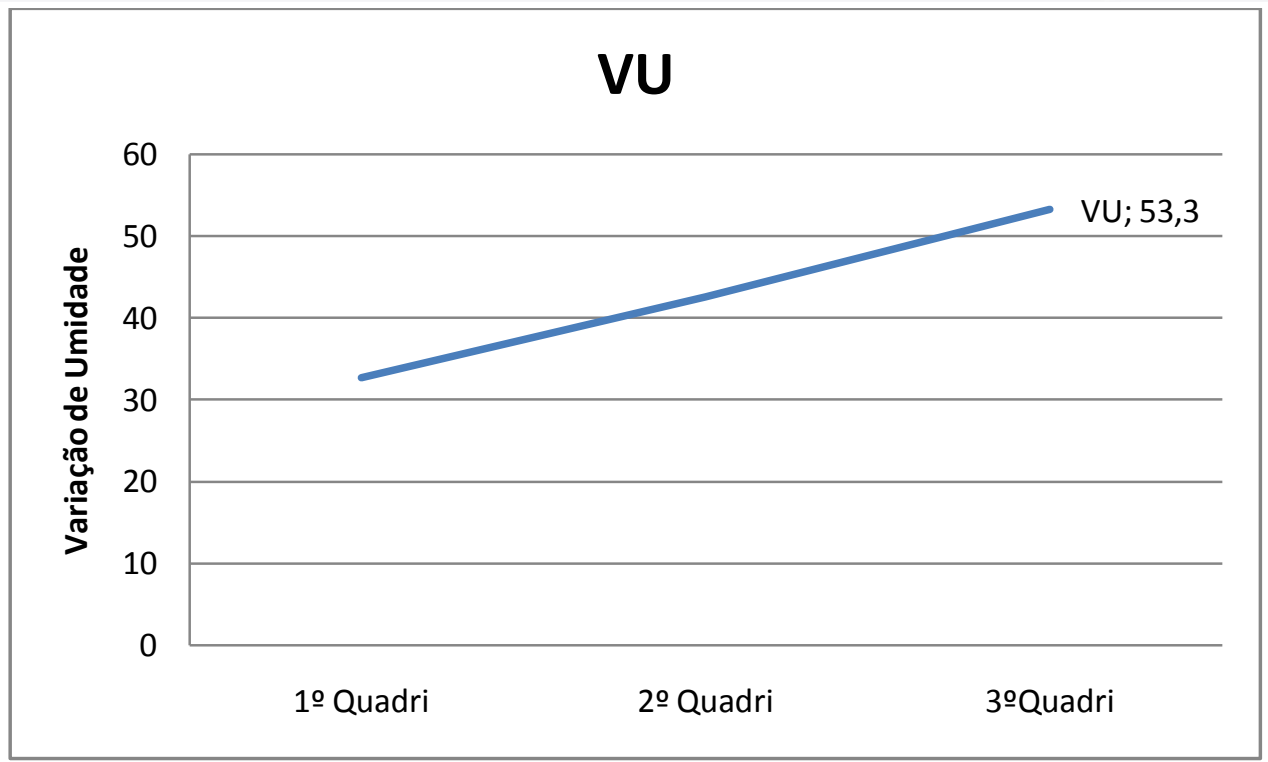

Fonte: Universidade Federal de Uberlândia- Departamento de Climatologia Org: Oliveira,L.L

Figura7: Gráfico Relação: Agravos Respiratórios por quadrimestre /Temperatura Mínima /Umidade

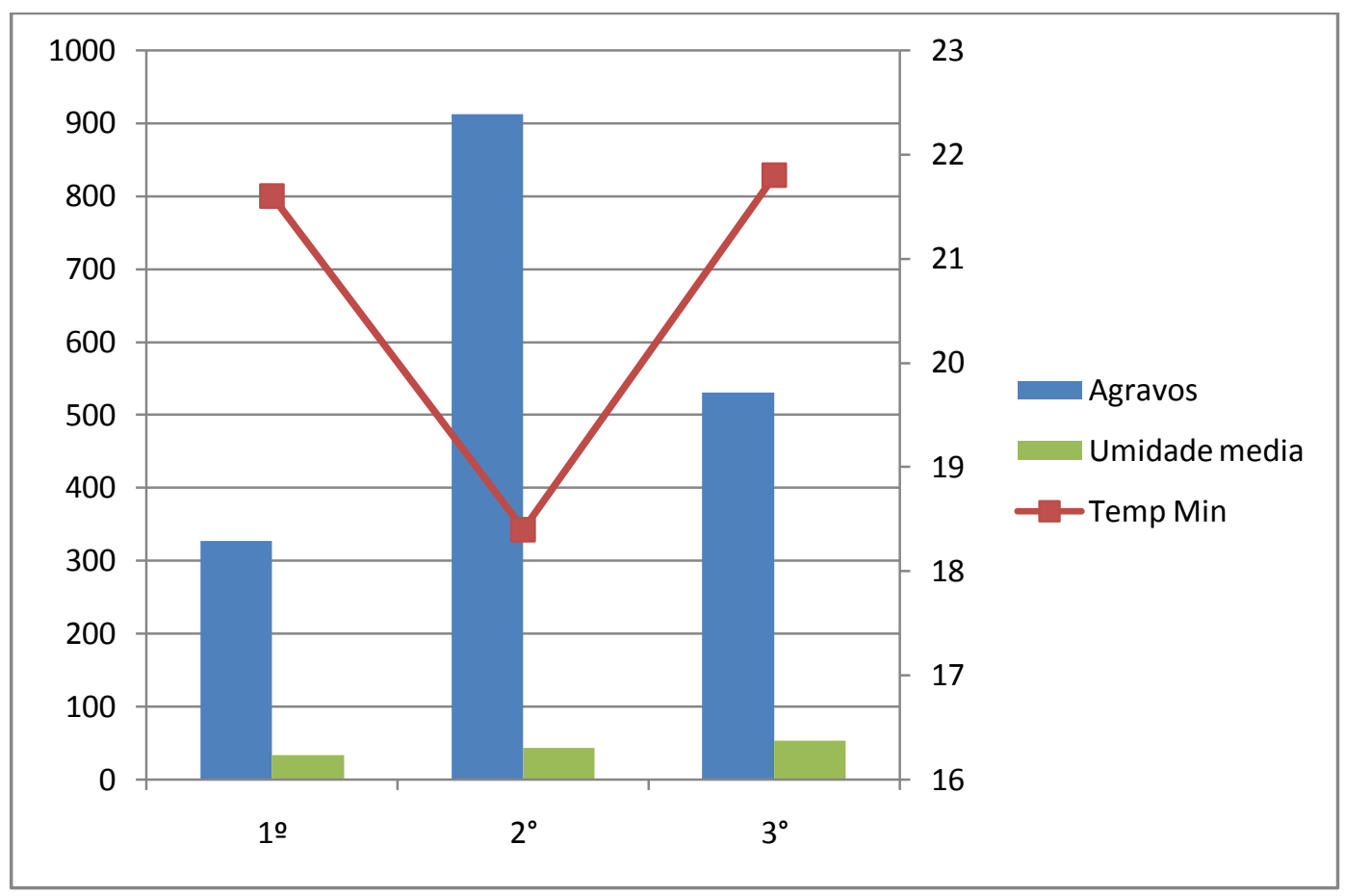

Fonte: Secretaria de Saúde/ Universidade Federal de Uberlândia Org: Oliveira, L.L

Na figura 7 foi possível observar que no segundo quadrimestre o número de crianças menores de cinco anos com problemas respiratórios foi maiores que do primeiro e terceiro quadrimestre, e houve no mesmo período meses temperaturas medias mais baixa. Este mesmo período manteve a umidade media abaixo da casa dos $50 \%$. 
No período que compreende janeiro a abril o numero de casos de crianças com problemas respiratórios notificados foi menor e a temperatura media maior, e a media da umidade relativa do ar ficou na casa $\operatorname{dos} 32,7 \%$.

\section{Considerações}

Partindo das analises dos dados tratados com os cálculos das médias o presente estudo permitiu a observação do clima e sua correlação com a procura pelo atendimento em saúde para problemas respiratórios em menores de cinco anos. Foi possível observar que a relação entre a temperatura e os casos de doenças respiratórias registrados, teve seu ápice no período que compreende os meses de maio a agosto onde foi registrado os valores mais baixos, nesse período a umidade relativa do ar ficou abaixo dos $45 \%$, é sabido que a umidade relativa do ar abaixo dos $50 \%$ causa desconforto para a população principalmente dos centros urbanos. Há necessidade de ressaltar que nesse período o aumento da poluição devido ao fator do aumento das queimadas urbanas e do fenômeno da inversão térmica que pode contribuir para o aumento dos casos de doenças respiratórias.

Analisando o período de janeiro a abril observamos que os casos de doenças respiratórias foram menores que dos segundo e terceiro quadrimestre, a media da temperatura foi mais elevada mantendo na casa dos $21,6^{\circ} \mathrm{C}$ mas houve o registro da media de umidade mais baixo dos três quadrimestre.

Portando, os dados observados no remete a analise que a temperatura baixa do período levou ao aumento dos casos de agravos respiratórios enquanto que a umidade relativa do apresentou influencia considerável visto que no primeiro quadrimestre a media da umidade relativa do ar manteve se abaixo do desejado.

Dessa forma , percebe se a necessidade de orientar a população e incentivar a pratica de medidas mitigadoscom relação a influencia do clima e do meio ambiente no agravamento das doenças respiratórias, podendo assim atenuar e prevenir os sintomas das mesmas.

\section{Bibliografia}

AYOADE, J. O. Introdução à Climatologia para os Trópicos. Tradução de Maria Juraci Zani dos Santos. 13ª ed. Rio de Janeiro: Betrand, 2010.

ARBEX, M. A. (Março/Abril de 2004). Queima de biomassa e efeitos sobre a saúde. Acesso em 17 de 07 de 2016, disponível em Jornal Brasileiro de Pneumologia: http://www.jornaldepneumologia.com.br/detalhe_artigo.asp?id=986

ASSOCIAÇÃO BRASILEIRA DE NORMAS TECNICAS, NBR 6023, informação e documentação, referências,elaboração: Rio de Janeiro, 2002.

CAJAZEIRA, A. A. GEOGRAFIA, AMBIENTE E SAÚDE. Correlação entre o clima e a incidencia de doenças respiratorias em Maacanaú/CE. 2012 
CONFALONIERI, U. E. C. Variabilidade climática, vulnerabilidade social e saúde no Brasil. Terra Livre, São Paulo, v.19, n.20, jan./jul., p.193-204. 2003.

DELATRE, E. D. (28 de 08 de 2004). www.queimadasurbanas.bmd.br. Acesso em 05 de 04 de 2016, disponível em Queimadas Urbanas: http://www.queimadasurbanas.bmd.br/

GUIMARÃES, E. N. Infraestrutura pública e movimento de capitais: a inserção de triangulo Mineiro na divisão inter-regional do trabalho. Dissertação de mestrado. Belo Horizonte: CEDPLAR/UFMG, 1990.

Mendes, P. C. A Gênese Espacial das Chuvas na Cidade de Uberlândia - Minas Gerais: Universidade Federal de Uberlândia, 2001. P. 237 (Dissertação de Mestrado em Geografia)

MENDONÇA, F. Aspectos da interação Clima - Ambiente - Saúde Humana: da Sociedade - Natureza a insustentabilidade ambiental. R. RAEGA: Espaço Geografico em Analise, Curitiba, n4. P85-89.2000. Editora UFPR.

MINISTERIO DA SAÚDE: Caderno da Atenção Básica: Doenças respiratórias Crônicas, Brasilia 2010.

MINISTÉRIO DA SAÚDE: Mudanças Climáticas e Saúde: ( serié: Saúde Ambiental 3) p7. Brasilia 2009

MOTA, H. M. Evolução urbanda de Uberlândia: uma cidade do triâgulo Mineiro de Porte Médio e em Contínuo Crescimento.Dissertação de Mestrado. PUC, Campinas, 2011.

SALDANHA, C. T , BOTELHO, C. Associações entre variaveis ambientais e asma em crianças atendidas no hospital publico. Rev. Bras. Alerg. Imunopatol - v31, n² . p50, 2008.

SILVA, E. M. O Clima da Cidade de Uberlândia - Minas Gerais. Revista Sociedade \& Natureza julho 2004

VARELLA, D. BRONQUITE DOENÇAS E SINTOMAS. Disponivel em / https://drausiovarella.com.br/doenças-e-sintomas/bronquite/ Acessoem 16 de março de 2017. 